\title{
АНТИРАДИКАЛЬНАЯ АКТИВНОСТЬ СПИРТОВЫХ ЭКСТРАКТОВ МАКРОМИЦЕТОВ С ПИЩЕВОЙ ЦЕННОСТЬЮ
}

\author{
() А.В. Ковалева ${ }^{1 *}$, А.С. Панкова ${ }^{1}$, И.И. Полохина ${ }^{2}$, С.Д. Трискиба ${ }^{2}$, Л.В. Каниболоцкая ${ }^{1}$, \\ М.Н. Сухомлин ${ }^{3}$, А.Н. Шендрик ${ }^{1}$ \\ ${ }^{1}$ Донецкий национальный университет, ул. Университетская, 24, Донецк, \\ 83001 (Украина), e-mail: sh@dongu.donetsk.ua \\ ${ }^{2}$ Центральная контрольно-исследовательская и проектно-изыскательная \\ водная лаборатория КП «Компания «Вода Донбасса», пр. Титова, 8, Донецк, \\ 83114 (Украина) \\ ${ }^{3}$ Институт биологии, Киевский национальный университет им. Тараса \\ Шевченко, ул. Глушкова, 2, Киев, 03187 (Украина)
}

Изучена антирадикальная активность спиртовых экстрактов 19 базидиальных грибов в реакциях с катионрадикалом 2,2'-азинобис(3-этилбензотиазолин)-6-сульфоновой кислоты и дифенилпикрилгидразилом. Наибольшей антирадикальной активностью в реакции с АБТС ${ }^{+\cdot}$ обладают этанольные экстракты сапротрофов $T r$. equestre, $V$. digitaliformis и микоризных симбиотрофов L. necator, B. edulis f. betulicola. В реакции с дифенилпикрилгидразилом высокая антирадикальная активность наблюдается у этанольных экстрактов симбиотрофов Rh. roseolus, B. edulis $f$. betulicola и сапротрофов X. badius, G. glutinosus.

Ключевые слова: макромицет, экстракт, антирадикальная активность, ДФПГ, катион-радикал АБТС.

\section{Введение}

Базидиомицеты являются ценным источником биологически активных соединений с иммуномодулирующим, адаптогенным, антиоксидантным действием [1-6]. Последнее связывается с наличием в составе плодового тела соединений фенольной природы, которые обладают антирадикальной активностью (AРA) [7]. В работах [8-11] показано, что фенольные соединения отвечают за антиоксидантное (антирадикальное) действие экстрактов. Однако анализ полученных результатов проводится на небольшой группе экстрактов макромицетов, что не позволяет систематизировать полученные данные, определить связь антирадикальной (антиоксидантной) активности и количества фенольных соединений в составе экстракта.

Ковалева Анастасия Вадимовна - аспирантка кафедры биохимии, e-mail: kovaleva.a@bk.ru

Панкова Александра Сергеевна - студентка кафедры биохимии

Полохина Ирина Ивановна - заведующая лабораторией биотехнологии и экологии

Трискиба Сергей Дмитриевич - заведующий отделом экологии

Каниболоцкая Людмила Викторовна - доцент кафедры биохимии, кандидат химических наук

Сухомлин Марина Николаевна - профессор, доктор биологических наук

Шендрик Александр Николаевич - декан химического факультета, заведующий кафедрой биохимии, доктор химических наук, профессор
Цель работы - изучение антирадикальной активности спиртовых экстрактов макромицетов, установление взаимосвязи между содержанием фенольных соединений в плодовом теле гриба и антирадикальным действием экстрактов.

\section{Экспериментальная часть}

Объектами исследования были этанольные экстракты плодовых тел высших базидиальных макромицетов Boletus edulis (Белый гриб), Lycoperdon perlatum (Дождевик жемчужный), Leccinum scabrum (Подберезовик обыкновенный), Leccinum aurantiacum (Подосиновик красный), Leccinum versipelle (Подо-

\footnotetext{
* Автор, с которым следует вести переписку.
} 
синовик красно-бурый), Hydnum repandum (Ежовик выемчатый), Lactarius necator (Груздь черный), Suillus luteus (Масленок обыкновенный), Tricholoma portentosum (Рядовка серая), Pleurotus ostreatus (Вешенка обыкновенная), Russula aurea (Сыроежка красная), Suillus bovinus (Козляк, решетник), Lactarius resimus (Груздь белый), Lyophyllum connatum (Рядовка сросшаяся), Gomphidius glutinosus (Мокруха клейкая), Xerocomиs badius (Польский гриб), Tricholoma equestre (Рядовка зеленая), Tricholoma albobrunneum (Рядовка бело-коричневая), Verpa digitaliformis (Верпа коническая), Rhizopogon roseolus (Ризопогон розовеющий), собранных в НПП «Святые горы» на территории Украины в сентябре-октябре 2010 гг. После сбора грибы сушили при комнатной температуре до постоянной массы и хранили в сухой стерильной емкости для исключения контаминации системы. Видовую принадлежность макромицетов определяли в соответствии с [12]. Все исследованные макромицеты имеют пищевую ценность.

Экстракцию из макромицетов проводили при температуре $(50,0 \pm 0,1){ }^{\circ} \mathrm{C} 96 \%$-м этанолом [13]. Для этого высушенные плодовые тела измельчали до порошкообразного состояния, отбирали по 0,25 г сырья, добавляли 25 мл спирта и проводили экстракцию в течение 3 ч.

Реакиия с АБТС . Катион-радикал АБТС $^{+\cdot}$ получали окислением $7 \cdot 10^{-3} \mathrm{M}$ водного раствора $2,2^{\prime}$-азинобис(3-этилбензотиазолин)-6-сульфоновой кислоты (АБТС) (Aldrich, UK) $2,45 \cdot 10^{-3} \mathrm{M}$ раствором персульфата калия $\left(\mathrm{K}_{2} \mathrm{~S}_{2} \mathrm{O}_{8}\right)$ [14]. Смесь оставляли в темном месте при комнатной температуре на 12 ч. Раствор АБТС ${ }^{+}$ разбавляли фосфатным буфером $(\mathrm{pH}=7,4)$ до оптической плотности $0,70 \pm 0,02$ при 734 нм $\left(\varepsilon_{A b T C}{ }^{+}=(1,6 \pm 0,1) \cdot 10^{4}\right.$ л/моль-см). К этому раствору прибавляли 0,2 мл спиртового раствора макромицета и записывали кинетические кривые расходования $\mathrm{ABTS}^{+\cdot}$ при различном разведении экстракта при $\mathrm{T}=293$ К. Антирадикальную активность спиртовых экстрактов макромицетов характеризовали величиной $\mathrm{TAEC}_{A Б T C}{ }^{+\cdot}$ (Trolox equivalent antioxidant capacity), численно равной общему числу радикалов, которые погибают на одной молекуле антиоксидантов [15]. Для вычисления ТАЕС из кинетических кривых расходования катион-радикала в реакции с тролоксом определили концентрацию прореагировавшего за 500 с АБТС ${ }^{+}$и построили зависимость этой концентрации от исходной концентрации тролокса. Получили линейную зависимость, тангенс угла наклона которой служит мерой антирадикальной активности. Такую же зависимость получили для спиртовых экстрактов каждого макромицета. ТАЕС определили как отношение тангенса угла наклона зависимости для спиртового экстракта макромицета к тангенсу угла наклона зависимости для тролокса.

Реакиия с ДФПГ. Рабочие растворы дифенилпикрилгидразила (ДФПГ, Koch-Light) готовили в 96\% этаноле [16]. Концентрацию ДФПГ подбирали таким образом, чтобы исходная оптическая плотность раствора была $(0,70 \pm 0,02)$ при 517 нм $\left(\mathrm{C}_{0}=(5,25 \pm 0,01) \cdot 10^{-5}\right.$ моль/л) $\left(\varepsilon=(1,33 \pm 0,04) \cdot 10^{4}\right.$ л/моль смм). Антирадикальную активность экстрактов макромицетов характеризовали величиной $\mathrm{TAEC}_{д Ф п Г}$, как описано выше для $\mathrm{ABTS}^{+}$.

Определение содержания фенольных соединений ( $\left.\mathrm{C}_{\Phi С}\right)$ по Фолину-Чикольте [17]. К 1 мл исследуемого образца приливали 5 мл разбавленного $1: 10$ реактива Фолина-Чикольте (Sigma, USA) в дистиллированной воде. Смесь перемешивали и оставляли на 5 мин. После чего добавляли 4 мл 7,5\%-го раствора $\mathrm{Na}_{2} \mathrm{CO}_{3}$ и оставляли на 2 ч при комнатной температуре в темном месте. По истечении времени измеряли оптическую плотность исследуемого образца при 740 нм против растворителя. Концентрацию фенольных соединений экстрактов оценивали в пересчете на концентрацию галловой кислоты (Aldrich, UK), для которой $\varepsilon=(1,51 \pm 0,04) \cdot 10^{3}$ л/моль $\cdot$ см.

Все спектроскопические измерения проводили на $U V$-VIS-спектрофотометре $C \Phi$-2000 (Россия) при $\mathrm{T}=298 \mathrm{~K}$.

Массу сухого остатка $\left(\mathrm{m}_{\mathrm{c} / \mathrm{o}}\right)$ определяли после выпаривания 25 мл экстракта и высушивания остатка в вакуумном шкафу до постоянной массы.

\section{Обсуждение результатов}

Этанольные экстракты исследованных макромицетов поглощают в области 260-300 нм (рис. 1). Косвенным подтверждением тому, что основная часть наблюдаемого поглощения обусловлена соединениями фенольной природы, является линейная зависимость величины оптической плотности в максимуме полосы поглощения от концентрации фенольных соединений в экстракте (рис. 2). 


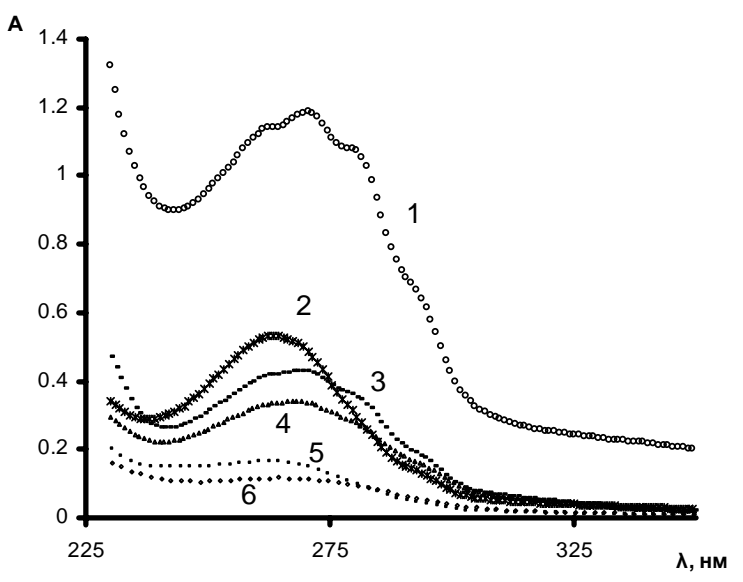

Рис. 1. $U V$-Vis-спектры этанольных экстрактов макромицетов: $1-S$. luteus $\left(C_{\phi c}=2,9 \cdot 10^{-5}\right.$ моль/л), $2-$ B. edulis $\left(C_{\phi c}=8, .8 \cdot 10^{-6}\right.$ моль/л),

3 - L. auratiacum $\left(C_{\phi c}=4,1 \cdot 10^{-5}\right.$ моль/л),

4 - L. scabrum $\left(C_{\phi c}=2,1 \cdot 10^{-5}\right.$ моль/л),

5 - L. perlatum $\left(C_{\phi c}=1,2 \cdot 10^{-5}\right.$ моль/л),

6 - L. necator $\left(C_{\phi c}=7,8 \cdot 10^{-6}\right.$ моль $\left./ л\right)$. Т $=298 \mathrm{~K}$
A

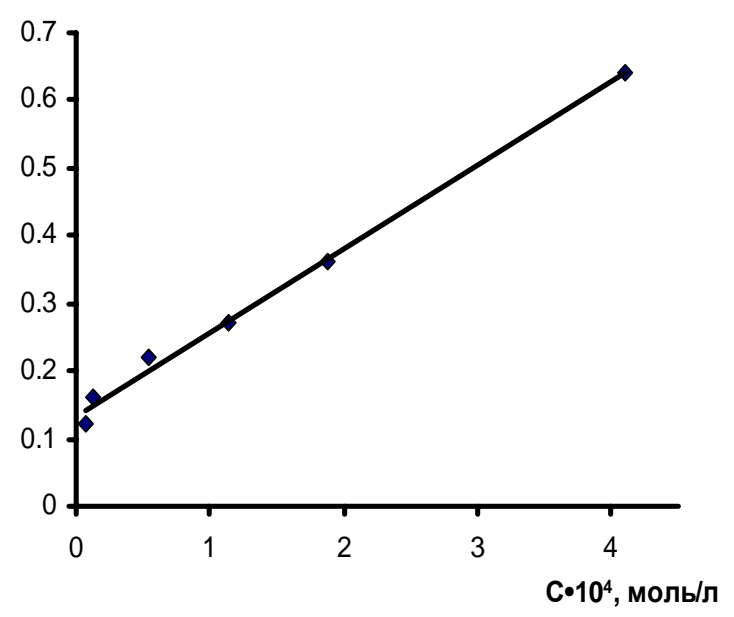

Рис. 2. Зависимость оптической плотности в максимуме поглощения от концентрации фенольных соединений в этанольных экстрактах макромицетов

Общее количество фенольных соединений в экстрактах макромицетов приведено в таблице. Наибольшее количество фенолов содержится в этанольном экстракте B. edulis.

При введении экстрактов в раствор ДФПГ наблюдается расходование последнего. Типичные кинетические кривые расходования радикала ДФПГ приведены на рисунке 3. Они состоят из двух участков быстрого падения оптической плотности в начале реакции ( 20 с) и последующего медленного расходования ДФПГ. Можно предположить, что скачкообразное уменьшение оптической плотности обусловлено быстрой реакцией ДФПГ с находящимися в экстрактах макромицетов фенольными соединениями, а более медленный процесс характеризует реакцию радикала с другими (нефенольными) компонентами экстрактов. Если это так, то между количеством прореагировавшего радикала на быстром участке кинетической кривой и начальной концентрацией фенолов должна быть линейная зависимость, что действительно и наблюдается (рис. 4). Это позволяет использовать количество быстропрореагировавшего радикала ДФПГ в качестве меры антирадикальной емкости фенольных соединений экстракта, а общее количество прореагировавшего ДФПГ за определенный промежуток времени (например, 500 с) - мерой антирадикальной активности (АРА) всех растворенных в экстракте соединений.

Наибольшей антирадикальной емкостью в реакции с ДФПГ обладает этанольный экстракт $R h$. roseolus. Антирадикальная активность спиртовых экстрактов макромицетов в реакции с радикалом ДФПГ находится на тролокса.

Аналогичные кинетические кривые получены для всех экстрактов и в реакции с АБТС ${ }^{+}$. На кинетических кривых зависимости оптической плотности от времени имеются 2 участка: первый, характеризующийся быстрым падением оптической плотности ( 20 с), и второй - с плавным снижением концентрации катион-радикала. Предполагается, что на первой стадии происходит перенос электрона с антиоксиданта на катион-радикал, а затем реакция протекает по механизму переноса атома водорода [18]. Наиболее высокая AРА в реакции с катион-радикалом наблюдается у микоризного сапротрофа Tr. equestre.

Между антирадикальной емкостью этанольных экстрактов в реакции с АБТС ${ }^{+•}$ и антирадикальной емкостью в реакции с ДФПГ нет корреляции $\mathrm{R}^{2}=0,0073$. То есть можно говорить о том, что механизм реакции этих двух радикалов с молекулами антиоксидантов различный. Если из зависимости исключить данные для спиртовых экстрактов макромицетов 3, 10, 16, 19 (табл.), то $\mathrm{R}^{2}=0,6174$ (рис. 5). Имеется корреляционная связь между величинами ТАЕС для этанольных экстрактов сапротрофов $\mathrm{R}^{2}=0,8427$ (не включены результаты по макромицетам 10, 16, 19 (табл.)) и слабая корреляция для экстрактов симбиотрофов $\mathrm{R}^{2}=0,3648$. 
Содержание фенольных соединений и антирадикальная активность спиртовых экстрактов макромицетов

\begin{tabular}{|c|c|c|c|c|c|}
\hline \multirow{2}{*}{ Название макромицета (лат) } & \multirow{2}{*}{ Экогруппа } & \multirow{2}{*}{$\mathrm{m}_{\mathrm{c} / \mathrm{o}} \cdot 10^{3}, \Gamma$} & \multirow{2}{*}{$\mathrm{C}_{\Phi C} \cdot 10^{4}, \mathrm{M}$} & \multicolumn{2}{|c|}{ TAEC } \\
\hline & & & & ${ }_{A B T S}^{+\cdot}$ & дФПГ \\
\hline Boletus edulis f. betulicola & Микоризный симбиотроф сосны & $92,5 \pm 0,1$ & $10,8 \pm 0,1$ & $0,5 \pm 0,1$ & $0,7 \pm 0,1$ \\
\hline Suillus luteus & Микоризный симбиотроф сосны & $65,0 \pm 0,1$ & $3,3 \pm 0,1$ & $1,4 \pm 0,1$ & $1,3 \pm 0,1$ \\
\hline Rhizopogon roseolus & Микоризный симбиотроф сосны & $32,5 \pm 0,1$ & $1,3 \pm 0,1$ & $1,1 \pm 0,1$ & $2,1 \pm 0,1$ \\
\hline Leccinum auratiacum & $\begin{array}{c}\text { Микоризный симбиотроф березы } \\
\text { и сосны }\end{array}$ & $57,5 \pm 0,1$ & $5,8 \pm 0,1$ & $0,7 \pm 0,1$ & $0,4 \pm 0,1$ \\
\hline Lactarius necator & Микоризный симбиотроф березы & $42,5 \pm 0,1$ & $3,0 \pm 0,1$ & $1,0 \pm 0,1$ & $0,6 \pm 0,1$ \\
\hline Leccinum scabrum & Микоризный симбиотроф березы & $77,5 \pm 0,1$ & $5,5 \pm 0,1$ & $0,6 \pm 0,1$ & $0,4 \pm 0,1$ \\
\hline Suillus bovinus & Симбиотроф & $112,5 \pm 0,1$ & $4,1 \pm 0,1$ & $0,7 \pm 0,1$ & $1,1 \pm 0,1$ \\
\hline Pleurotus ostreatus & Древесный сапротроф & $17,5 \pm 0,1$ & $2,8 \pm 0,1$ & $0,9 \pm 0,1$ & $1,1 \pm 0,1$ \\
\hline Tricholoma albobrunneum & Древесный сапротроф & $42,5 \pm 0,1$ & $1,9 \pm 0,1$ & $0,9 \pm 0,05$ & $1,1 \pm 0,1$ \\
\hline Russula aurea & Подстилочный сапротроф & $37,5 \pm 0,1$ & $2,4 \pm 0,1$ & $1,9 \pm 0,1$ & $0,25 \pm 0,01$ \\
\hline Lactarius resimus & Гумусовый сапротроф & $10,0 \pm 0,1$ & $1,5 \pm 0,1$ & $0,6 \pm 0,1$ & $0,5 \pm 0,1$ \\
\hline Lycoperdon perlatum & Гумусовый сапротроф & $55,0 \pm 0,1$ & $7,1 \pm 0,1$ & $0,6 \pm 0,1$ & $0,4 \pm 0,1$ \\
\hline Hydnum repandum & Гумусовый сапротроф & $12,5 \pm 0,1$ & $3,2 \pm 0,1$ & $1,3 \pm 0,1$ & $1,4 \pm 0,1$ \\
\hline Lyophyllum connatum & Гумусовый сапротроф & $36,0 \pm 0,1$ & $2,3 \pm 0,1$ & $0,7 \pm 0,1$ & $0,9 \pm 0,1$ \\
\hline Gomphidius glutinosus & Гумусовый сапротроф & $27,5 \pm 0,1$ & $3,3 \pm 0,1$ & $1,2 \pm 0,2$ & $1,6 \pm 0,1$ \\
\hline Verpa digitaliformis & Гумусовый сапротроф & $32,5 \pm 0,1$ & $0,55 \pm 0,05$ & $1,77 \pm 0,05$ & $0,7 \pm 0,1$ \\
\hline Tricholoma portentosum & Микоризный сапротроф сосны & $87,5 \pm 0,1$ & $1,3 \pm 0,1$ & $0,4 \pm 0,5$ & $0,50 \pm 0,08$ \\
\hline Xerocomus badius & $\begin{array}{c}\text { Микоризный сапротроф с хвой- } \\
\text { ными и лиственными деревьями, } \\
\text { реже почвенный }\end{array}$ & $55,0 \pm 0,1$ & $2,8 \pm 0,1$ & $1,1 \pm 0,2$ & $1,7 \pm 0,1$ \\
\hline Tricholoma equestre & $\begin{array}{c}\text { Микоризный сапротроф с хвой- } \\
\text { ными и лиственными деревьями, } \\
\text { реже почвенный }\end{array}$ & $22,5 \pm 0,1$ & $1,9 \pm 0,1$ & $4,8 \pm 0,2$ & $0,9 \pm 0,1$ \\
\hline
\end{tabular}

A

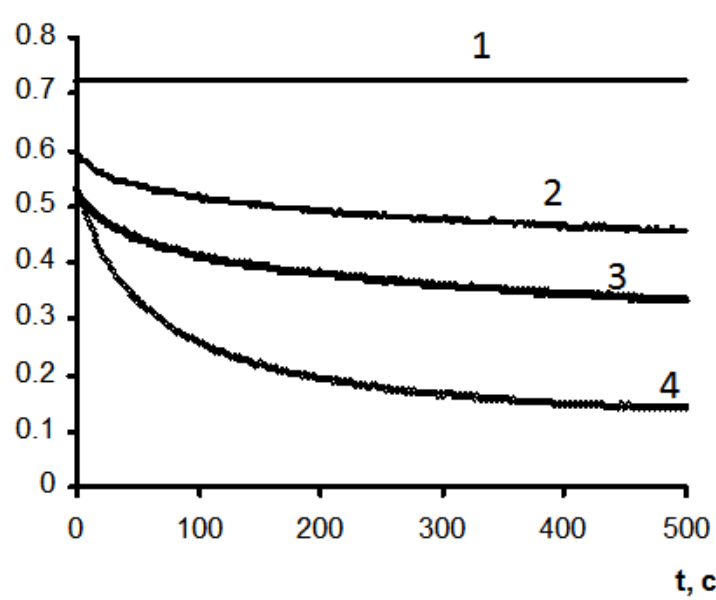

Рис. 3. Кинетические кривые расходования

ДФПГ: 1 - без добавок экстрактов, в присутствии экстрактов, $2-$ L. auratiacum $\left(\mathrm{C}_{\mathrm{\phi c}}=5,6 \cdot 10^{-5}\right.$ моль/л), 3 - L. scabrum ( $\mathrm{C}_{\phi c}=6,2 \cdot 10^{-5}$ моль/л), 4 -

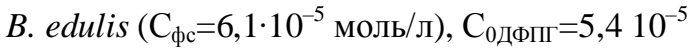
моль/л

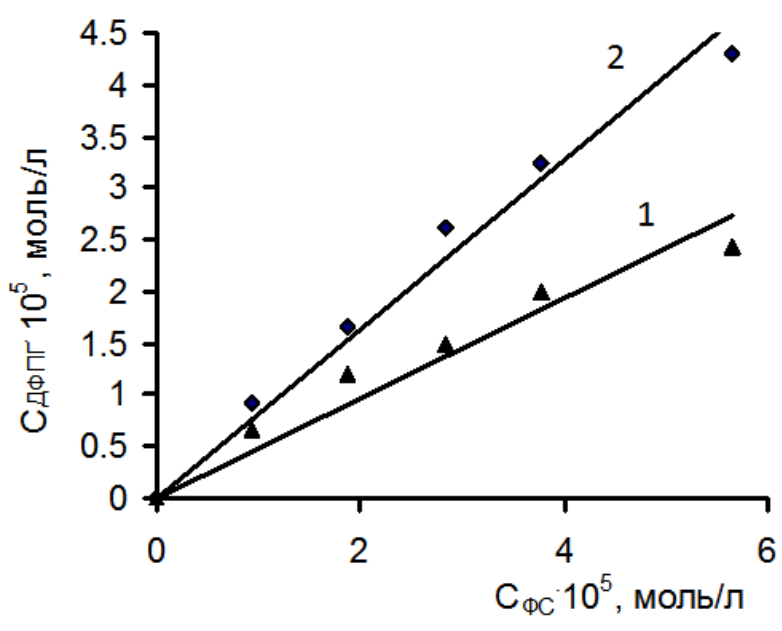

Рис. 4. Зависимость концентрации прореагировавшего ДФПГ от начальной концентрации фенольных соединений в этанольном экстракте Suillus luteus:

1 - по истечении $20 \mathrm{c}, 2-500 \mathrm{c}$.

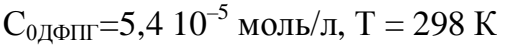

Между содержанием фенольных соединений в этанольных экстрактах макромицетов, определенных по методу Фолина-Чикольте, и массой сухого остатка имеется слабая корреляция $\left(\mathrm{R}^{2}=0,2665\right)$ в общем ряду данных. Если из зависимости исключить результаты по экстрактам макромицетов 2, 7, 8, 13, 17, то получается хорошая корреляционная связь между этими параметрами $\left(\mathrm{R}^{2}=0,714\right)$ (рис. 6). То есть, вероятно, этанольные экстракты исследованных макромицетов содержат в основном фенольные соединения структурные аналоги галловой кислоты. 


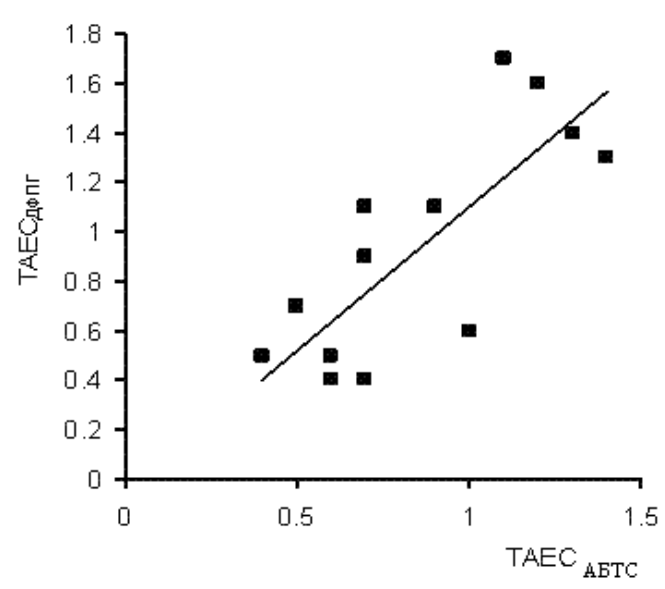

Рис. 5. Зависимость антирадикальной емкости фенольных соединений в реакции с ДФПГ от антирадикальной емкости в реакции с АБТС ${ }^{+}$.

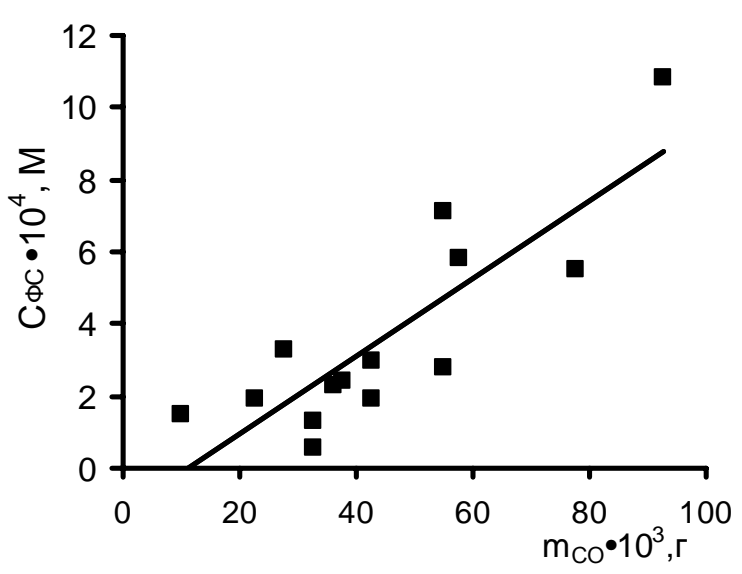

Рис. 6. Зависимость концентрации фенольных соединений экстрактов макромицетов от массы сухого остатка

\section{Выводы}

Спиртовые экстракты высших базидиальных грибов проявляют антирадикальные свойства. Антиоксидантная емкость большинства этанольных экстрактов макромицетов выше или находится на уровне водорастворимого аналога витамина $\mathrm{E}$ - тролокса. Наибольшей антирадикальной активностью в реакции с АБТС $^{+\cdot}$ обладают этанольные экстракты сапротрофов $T r$. equestre, V. digitaliformis и микоризных симбиотрофов L. necator, B. edulis f. betulicola. В реакции с дифенилпикрилгидразилом высокая антирадикальная активность наблюдается у этанольных экстрактов симбиотрофов Rh. roseolus, B. edulis f. betulicola и caпротрофов X. badius, G. glutinosus.

\section{Список литературы}

1. Cui Y., Kim D.G., Park K.C. Antioxidant effect of Inonotus obliquus // Journal of Ethnopharmacology. 2005. N96. Pp. 79-85.

2. Hu H., Zanng Z., Lei Z., Yang Y., Sugiura N. Comparative study of antioxidant activity and antiproliferativ effect of hot water and ethanol extracts from the mushroom Inonotus obiquus // Journal of Bioscience and Bioengineering. 2009. Vol. 107, N1. Pp. 42-48.

3. Sirag H.M. Biochemical and Hematological Studies for the Protective Effect of Oyster Mushroom (Pleuratus ostreatus) Agints Glycerol-Induced Acute Renal Failure in Rats // Journal of Biological Sciences. 2009. Vol. 7, N9. Pp. 746-752.

4. Putaragu N.G., Vevkateshaian S. U., Dharmesh S.M. Antioxidant activity of indigenous edible mushrooms // J Agric Food Chem. 2006. N54. Pp. 9764-9772.

5. Hu H., Zanng Z., Lei Z., Yang Y., Sugiura N. Comparative study of antioxidant activity and antiproliferativ effect of hot water and ethanol extracts from the mushroom Inonotus obliquus // Journal of Bioscience and Bioengineering. 2009. Vol. 107, N1. Pp. 42-48.

6. Samchai S., Seephonkai P., Sangdee A., Puntumchai A. Antioxidant, Cytotoxid and antimalarial activities from crude extracts of mushroom Phellinus linteus // Journal of Biological Sciences. 2009. Vol. 7, N9. Pp. 778-783.

7. Kim M.Y., Seguin P., Ahn J.K., Kim J.J., Chun S.C., Kim E.H., Kang E.Y. Phenolic compound concentration and antioxidant activities of edible and medicinal mushrooms from Korea // J Agric Food Chem. 2008. N56. Pp. 7265-7270.

8. Venkatakrishnan V., Shenbhagaraman R., Kaviyarasan V., Gunasundari D., Radhika K., Dandapani R., Loganathan K. Jagadish. Antioxidant and antiproliferative effect of Pleurotus ostreatus // Journal of Phytology. 2010. Vol. 2, N1. Pp. 022-028.

9. In-Kyoung Lee, Bong-Sik Yun. Hispidin analogs from the mushroom Inonotus xeranticus and their free radical scavenging activity // Bioorganic \& Medicinal Chemistry Letters. 2006. Vol. 16. Pp. 2376-2379.

10. de Bruijn J., Loyola C., Aqueveque P., Canumir J., Cortez M., France A. Antioxidant properties of extracts obtained from Grifola gargal mushrooms // Micologia Aplicada International. 2009. Vol. 21, N1. Pp. 11-18.

11. Kim M.-Y., Seguin P., Ahn J.-K., Kim J.-J., Chun S.-C., Kim E.-H., Seo S.-H., Kang E.-Y., Kim S.-L., Park Y.-J., Ro H.-M., Chung I.-M. Phenolic compound concentration and antioxidant activities of edible and medicinal mushrooms from Korea // J. Agric. Food Chem. 2008. Vol. 56. Pp. 7265-7270.

12. Вассер С.П. Высшие базидиомицеты степной зоны Украины. Киев, 1977. 356 с.

13. Ооржак У.С., Ушанова В.М., Репях С.М. Исследование влияния технологических факторов на процесс извлечения экстрактивных веществ из лиственной губки // Химия растительного сырья. 2003. №1. С. 69-72.

14. Re R., Pellegrini N., Proteggente A., Pannala A. Antioxidant activity applying an improved ABTS radical cation decolorization assay // FRBM. 1999. Vol. 26, N9/10. Pp. 1231-1237. 
15. Walker R.B., Everette J.D. Comparative reaction rates of various antioxidants with ABTS radical cation // J. Agric. Food Chem. 2009. Vol. 57, N4. Pp. 1156-1161.

16. Goupy P., Dufour C., Loonis M. Quantitative kinetic analysis of hydrogen transfer reactions from dietary polyphenols to the DPPH radical // J. Agric. Food Chem. 2003. Vol. 51, N3. Pp. 615-622.

17. Singleton V.L., Orthofer R., Lamuela-Raventos R.M. Analisis of total phenols and other oxidation substrates and antioxidants by means of Folin-Ciocalteu reagent // Methods in Enzymology. 1999. Vol. 299. Pp. 152-157.

18. Tang Y.-Z., Liu Z.-Q. Free-radical-scavenging effect of carbazole derivatives on DPPH and ABTS radicals // J. Am. Oil Chem. Soc. 2007. Vol. 84. Pp. 1095-1100.

Поступило в редакичию 12 февраля 2013 г.

После переработки 26 мая 2013 г.

Kovalova A.V. ${ }^{{ }^{*},}$, Pankova A.S. ${ }^{1}$, Polokhina I.I. ${ }^{2}$, Triskiba S.D. ${ }^{2}$, Kanibolotskaya L.V. ${ }^{1}$, Sukhomlin M.N. ${ }^{3}$, Shendrik A.N. ${ }^{1}$ ANTIRADICAL ACTIVITY OF ETHANOLIC EXTRACTS OF MACROMYCETES WITH FOOD VALUE

${ }^{1}$ Donetsk National University, Universitetskaia st.,24, Donetsk, 83001 (Ukraine), e-mail: sh@dongu.donetsk.ua

${ }^{2}$ Central control and research and design and survey water laboratory manual "Company" Water of Donbas", Titova ave., 8, Donetsk, 83114 (Ukraine)

${ }^{3}$ Институт биологии, Киевский национальный университет им. Тараса Шевченко, Glushkova st., 2,Kiev, 03187

(Ukraine)

The antiradical activity of 19 basidiomycetes ethanolic extracts was studied in the reactions with cation-radical of 2,2'azinobis(3-ethylbenzthiazoline)-6-sulfonic acid and diphenylpicrylhydrazyl. The ethanolic extracts of saprotrophs Tr.equestre and V.digitaliformis and mycorrhizal simbiotrophs L. necator, B. edulis f.betulicola possess the highest antiradical activity in the reaction with $\mathrm{ABTS}^{+}$. In the reaction with DPPH the highest antiradical activity was observed in ethanol extracts of simbiotrofs Rh. roseolus, B. edulis f. betulicola and saprotrophs X. badius, G. glutinosus.

Keywords: macromycetes, extracts, antiradical activity, DPPH, $\mathrm{ABTS}^{+\bullet}$

\section{References}

1. Cui Y., Kim D.G., Park K.C. Journal of Ethnopharmacology, 2005, no. 96, pp. 79-85.

2. Hu H., Zanng Z., Lei Z., Yang Y., Sugiura N. Journal of Bioscience and Bioengineering, 2009, vol. 107, N1, pp. 42-48.

3. Sirag H.M. Journal of Biological Sciences, 2009, vol. 7, no. 9, pp. 746-752.

4. Putaragu N.G., Vevkateshaian S. U., Dharmesh S.M. J Agric Food Chem., 2006, no. 54, pp. 9764-9772.

5. Hu H., Zanng Z., Lei Z., Yang Y., Sugiura N. Journal of Bioscience and Bioengineering, 2009, vol. 107, no. 1, pp. 42-48.

6. Samchai S., Seephonkai P., Sangdee A., Puntumchai A. Journal of Biological Sciences, 2009, vol. 7, no. 9, pp. $778-783$.

7. Kim M.Y., Seguin P., Ahn J.K., Kim J.J., Chun S.C., Kim E.H., Kang E.Y. J Agric Food Chem., 2008, no. 56, pp. $7265-7270$.

8. Venkatakrishnan V., Shenbhagaraman R., Kaviyarasan V., Gunasundari D., Radhika K., Dandapani R., Loganathan K. Jagadish. Journal of Phytology, 2010, vol. 2, no. 1, pp. 022-028.

9. In-Kyoung Lee, Bong-Sik Yun. Bioorganic \& Medicinal Chemistry Letters, 2006, vol. 16, pp. 2376-2379.

10. de Bruijn J., Loyola C., Aqueveque P., Canumir J., Cortez M., France A. Micologia Aplicada International, 2009, vol. 21, no. 1, pp. 11-18.

11. Kim M.-Y., Seguin P., Ahn J.-K., Kim J.-J., Chun S.-C., Kim E.-H., Seo S.-H., Kang E.-Y., Kim S.-L., Park Y.-J., Ro H.-M., Chung I.-M. J. Agric. Food Chem., 2008, vol. 56, pp. 7265-7270.

12. Vasser S.P. Vysshie bazidiomitsety stepnoi zony Ukrainy. [Higher Basidiomycetes steppe zone of Ukraine.]. Kiev, 1977, 356 p. (in Russ.).

13. Oorzhak U.S., Ushanova V.M., Repiakh S.M. Khimiia rastitel'nogo syr'ia, 2003, no. 1, pp. 69-72. (in Russ.).

14. Re R., Pellegrini N., Proteggente A., Pannala A. FRBM, 1999, vol. 26, no. 9/10, pp. 1231-1237.

15. Walker R.B., Everette J.D. J. Agric. Food Chem., 2009, vol. 57, no. 4, pp. 1156-1161.

16. Goupy P., Dufour C., Loonis M. J. Agric. Food Chem., 2003, vol. 51, no. 3, pp. 615-622.

17. Singleton V.L., Orthofer R., Lamuela-Raventos R.M. Methods in Enzymology, 1999, vol. 299, pp. 152-157.

18. Tang Y.-Z., Liu Z.-Q. J. Am. Oil Chem. Soc., 2007, vol. 84, pp. 1095-1100.

Received February 12, 2012

Revised May 26, 2013

\footnotetext{
* Corresponding author.
} 